\title{
Supporting Emergent Writers Through Guided Play in a Kindergarten Classroom
}

\author{
Nicola Friedrich, Kristen Wishart, and Shelley Stagg Peterson
}

Nicola Friedrich is a postdoctoral fellow at the University of Toronto. She is participating in the research partnership project to assess and support young children's oral language and writing development through play. She previously worked as a classroom teacher, reading clinic teacher, and special subject tutor. Email: n.friedrich@utoronto.ca

Kristen Wishart is an early childhood educator with the Rainy River District School Board, where she co-teaches in a kindergarten classroom.

A former elementary teacher, Shelley Stagg Peterson is a professor at the University of Toronto and principal investigator of a research partnership project, collaborating with kindergarten and grade 1 teachers in northern school divisions and First Nations communities to conduct research on children's oral language and writing in play contexts.

In this paper, we describe a teacher-initiated a kindergarten classroom in a small northern town in Ontario, Canada. The Fairy Door scenario afforded the 3- to 5-year-old children the opportunity to become writers in order to communicate with and make sense of an elusive with opportunities to scaffold the children's writing attempts and provided them with valid assessments of the children's understanding of texts and writing. We offer this unique form of pedagogical practice as a means to fulfill the provincial curriculum.

Keywords: emergent writing; rural education; guided play; kindergarten; pedagogical practice imaginative-play scenario that took place in visitor to the classroom. It presented the teachers play-based learning mandate of the Ontario

Recent research in early childhood education has identified teacher-guided activities that support emergent writers in the classroom. These research-based activities include writers' workshop and dictation within storybook reading (e.g., Dennis \& Votteler, 2013), interactive writing (e.g., A. Hall, 2016), and using content-specific props (e.g., Byington \& Kim, 2016). Research has also identified specific teacher actions that support young children's development as writers, including scaffolding strategies such as modelling, guiding, and extending (Quinn, Gerde, \& Bingham, 2016), stocking all areas of the classroom with writing materials, and making available to children opportunities to engage in meaningful writing (Gerde, Bingham, \& Wasik, 2012).

Literacy researchers have suggested that, in early childhood, play relates to literacy in that, according to Nigel Hall (1991), it "provides a context within which the emergence of literacy can be manifested and explored" (p. 20). Drawing largely from Lev Vygotsky (1978), they understand a specific form of play in preschool and primary classrooms, dramatic play, as a meaning-making and narrative-building practice (Wajskop \& Peterson, 2015) during which children engage in symbolic thinking and become avid sign makers (Peterson, 2015). They suggest this form of play also provides a motivating and authentic context in which children can write (Peterson \& Portier, 2016; Worthington \& van Oers, 2017).

Other educational researchers conceptualize play as a pedagogical tool available to teachers for developing mathematical concepts (e.g., Fisher, Hirsh-Pasek, Newcombe, \& Golinkoff, 2013) and fostering and extending children's language (e.g., Wasik \& Jacobi-Vessels, 2017). Scaffold (Wasik \& Jacobi-Vessels, 2017) or guided play is a blend of adult-initiated and child-directed activity during which children are understood as being decision makers directing their form of response and determining suitable next steps. The teachers' role in guided play includes 
preparing the physical space beforehand and scaffolding the children's participation during the child-directed activities by asking them questions while they play, providing meaningful feedback, or introducing objects or ideas as a means to redirect or extend the activity (Weisberg et al., 2015).

However, much of the research on guided play is situated within the preschool context. We understand guided play as an appropriate pedagogical practice in kindergarten. Our purpose in writing this paper is to describe guided play in the form of a teacher-initiated imaginative scenario within a kindergarten classroom. We begin by setting the context in which the scenario took place. Next, we describe both the children's and adults' roles during the month-long scenario. We conclude by discussing the guided-play-inspired imaginative scenario as a pedagogical practice to support young children's emergent writing in kindergarten.

\section{Context}

Joan and Leslie's (all names are pseudonyms) kindergarten class is located in an elementary school in a small northern town in Ontario, Canada. In Ontario, the kindergarten program is a two-year program. A typical kindergarten class includes Year 1 (ages 3-4) and Year 2 (ages 4-5) children and is co-taught by a teacher and an early childhood educator (ECE). The curriculum is play based. Teachers are expected to provide for children a safe and resource-rich environment for play and allow such play to unfold without adult interference (Peterson et al., 2016).

\section{Fairy Door: An improvised imaginative scenario}

\section{Initiating the scenario}

Joan and Leslie wanted to create opportunities for students to direct their own learning within their classroom. On a whim, they placed a miniature door under a table in a corner of the room. One day, as the children filed into the classroom, Joan and Leslie stood near the door and talked quietly to each other about the door's unexpected appearance. In no time, the children noticed the door and began to ask questions. Rather than providing them with answers, Joan and Leslie encouraged the children to come up with suggestions as to how they might discover the identity of what or who might be living behind the door. Some of the children suggested laying a trap just outside the door. Then, working collaboratively, many of the children designed and constructed a number of small traps and placed them on the floor in front of the miniature door. One child soon voiced her objections to the construction of the traps. After the children had gone home for the day, Joan and Leslie sided with the protester and removed the traps. Taking on the role of a fairy named Lily, Leslie then wrote a letter to the children, saying that she would make her home in the classroom so long as they stopped trying to catch her. She placed the letter in front of the door. The next morning, after hearing of Lily's request, many of the children wrote letters of apology to Lily.

\section{Extending the scenario}

During the weeks that followed, to create the illusion that Lily actually lived behind the door, Leslie made small accessories (e.g., a fence, a mailbox) and left them around the door. In response, many children initiated the writing of their own notes or letters to Lily to comment on or ask questions about the items. Joan and Leslie often assisted individual children in the act of writing by scaffolding their writing of individual words. For example, Leslie made a miniature bike out of wire and propped it up on the wall next to the door after school hours. One Year 2 student had a question about the bike and decided to write a letter to Lily for the answer. The following is an excerpt from a conversation between the student (G1) and Leslie (T1) as she wrote the letter: 


\author{
G1: $\quad$... bike for us? \\ T1: What are you writing? \\ G1: Is the bike, Dear Lily, is the bike for us? \\ T1: It's for $/ \mathrm{u} / \mathrm{s} /$. You can stretch that word out. \\ G1: (positions pencil in order to write) $/ \mathrm{u} /, / \mathrm{u} /, / \mathrm{u}$. \\ T1: What do you hear? \\ G1: (makes individual sounds) / $\mathrm{u} / \mathrm{s} /$ \\ $\mathrm{T} 1: \quad / \mathrm{u} / \mathrm{s} /$. \\ G1: (writing word as "Uas") /u/ /s/
}

In this example, the student initiated writing a specific genre of text, a personal letter, to ask about the bike. Leslie scaffolded the student's attempt at writing the word "us" by asking her a question. The student then read what she had written, questioning the word she was attempting to write. In response, Leslie first modelled and then suggested a strategy for identifying the individual sounds in the word. The student attempted to apply the strategy to the word she was writing. Leslie further prompted her to listen to the individual sounds and then stretched out the word as a way to affirm the sounds the student had identified. The student repeated the sounds she heard as she wrote the word. Her inclusion of the letter "a" suggested she was unclear as to which letter to associate with the $/ \mathrm{u} /$ sound.

By composing the text within the imaginative scenario, the Year 2 student provided Joan and Leslie with a valid assessment of her understanding of texts and writing. For example, while observing the student as she wrote, Leslie made note of the fact that the child had produced a specific genre of text, the personal letter, using conventional letters and that she intended these letters to represent sounds in words. As such, Leslie chose not to correct the student's spelling of the word "us". Furthermore, she noted that the student wrote in a complete sentence with appropriate punctuation and included a feature specific to a personal letter, the salutation (see Figure 1).

At other times, Joan and Leslie assisted the kindergarten students with reading their notes and letters. The following is an excerpt of a conversation between Leslie (T1) and a Year 2 student (B1) after he had finished composing and writing a letter to Lily:

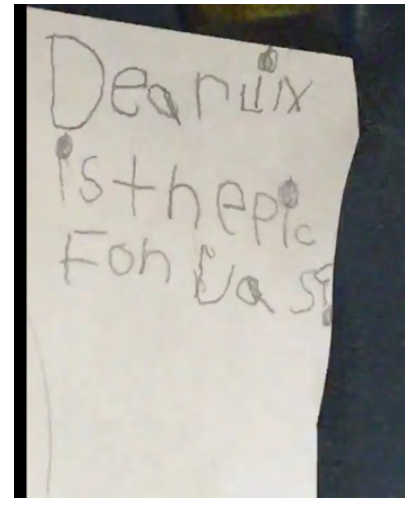

Figure 1. Letter to Lily

\title{
words) Dear Lily ... \\ B1: I ... No. Dear ... Dear Li, Lily \\ T1: What are you doing today? \\ B1: What are you doing today? \\ T1: Awesome!
}

B1: Dear Lily, I like your door (student's fingers can be seen hovering over individual letters and

In this example, since the student had completed writing his letter to Lily, Leslie prompted him to read his message. 
The child read the text out loud, hesitating on and repeating individual words. Leslie prompted him to continue by reading the next sentence of the text. The child then repeated the sentence on his own.

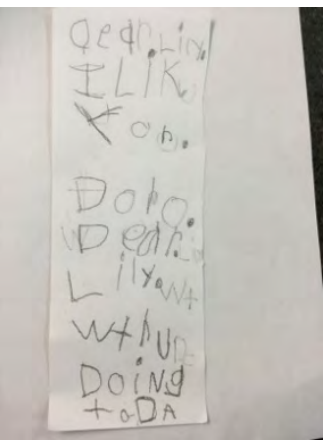

Figure 2. Letter to Lily

As was the case in the first example (see above), the imaginative scenario provided Joan and Leslie with a valid assessment opportunity of the Year 2 student's writing. In this second example, Joan and Leslie observed that the student had composed a specific genre of text, a letter, using conventional letters and intended these letters to represent sounds in words. They noted that he had included a feature specific to this genre of text, the salutation. However, his repeating of the salutation within the text suggested he was unclear as to the purpose of this feature. Joan and Leslie further noted that the student had written his message to Lily in complete sentences and had attempted to incorporate correct punctuation (see Figure 2).

As the month progressed, Joan and Leslie initiated other fairy-related activities to support the imaginative scenario. For example, after they overheard the children talking about fairy gardens, they initiated an activity in which the children designed and built their own fairy gardens. Similarly, after the children indicated that they would like to do something with Lily outside of the classroom, Joan and Leslie set out craft materials and invited the children to design and construct their own fairy to take home.

Following the home visit, Joan and Leslie initiated and directed a writing activity by providing the children with a template for writing a narrative about an experience they had shared with their fairy at home. The following is an excerpt of a conversation between Leslie (T1) and a Year 1 student (B1) as he completed his narrative:

T1: $\quad$ What did you write? Can you read it to me?

B1: I am playing Mario Kart with, with

T1: $\quad$ With my

B1: With my fairy. (B1completes writing the word "fairy." He repeats the word slowly to himself as he writes each letter.)

T1: Write what you can.

Prior to this particular writing event, Joan and Leslie provided each student with a printed template that included space for a picture and lines for a narrative. In this example, the student had played the video game Mario Kart at home with his fairy. Joan and Leslie observed that he represented this experience as a picture using identifiable images, intending these images to represent a character (i.e., the fairy) in a setting (i.e., the race car). They understood that the Year 1 student further communicated meaning in his picture by including details such as wheels and a frame in order to create the setting and by drawing the character in a seated position with outstretched arms. The Year 1 student wrote the accompanying text as a complete sentence using inconsistently sized conventional letters. Although he intended these letters to represent complete words (e.g., I, my, fairy) or the salient sounds within words (e.g., pring, Mreo), the student did not leave spaces between the words. Finally, Joan and Leslie noted that he began the sentence with a capital letter and ended it with a period (see Figure 3 ).

\section{Ending the scenario}

By the end of the month, Joan and Leslie noticed the kindergarten children's interest in Lily had waned. Leslie, in the role of Lily, wrote one final letter to the children. In it, she thanked them for letting her live in the classroom and wished them well in the year ahead. She then told the children she was heading out to see the world. As a 
means to keep their options open for next year, Leslie, as Lily, suggested she might return to the classroom one day.

\section{Pedagogical practice}

Our purpose in writing this paper was to share a teacher-initiated imaginative scenario within a kindergarten classroom in a small northern community in Ontario. We described what the teachers called the Fairy Door scenario, an improvised imaginative scenario that motivated the children to direct their own responses within teacher- and child-initiated activities in order to establish and extend the plotline within the scenario. We offer this imaginative scenario as an example of a guided-play-inspired pedagogical practice to support children's literacy learning in the kindergarten classroom.

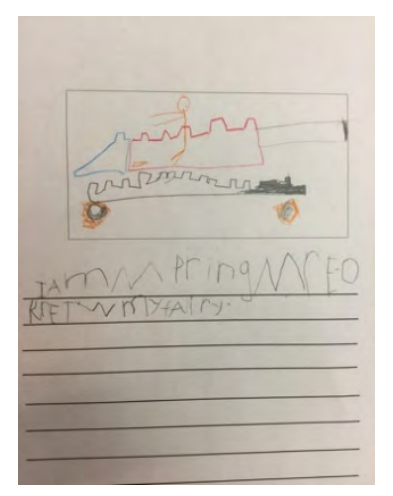

Figure 3. Narrative.

Although Joan and Leslie participated in the Fairy Door scenario, we suggest this unique form of pedagogical practice fulfills the play-based learning mandate of the Ontario kindergarten program (Ontario Ministry of Education, 2016). Joan and Leslie's decision to use the miniature door to engage their students in an improvised imaginative plotline involving a mysterious visitor who makes a home in their classroom embodies the spirit of guided play (Weisberg et al., 2013). For example, Joan and Leslie initiated the plotline by placing a miniature door under the table and then talking about the door as the children filed into the classroom. As the day progressed, they followed the children's direction and provided them with the time, space, and materials to design and build traps. After listening to a fairy door protester, they decided to intervene in the developing plotline and steer the children away from the idea of trapping the visitor. Instead, they initiated the idea of writing a letter as an alternative method for discovering the visitor's identity. Overall, the children directed their own responses to teacher-initiated activities within the scenario. As described above, they began by collaborating with others to plan and build traps. After receiving Lily's letter, they participated in the plotline by writing their own letters.

Throughout the month-long scenario, the children chose to extend the fairy plotline through written communications with Leslie (in the role of the fairy Lily). Thus, rather than introducing a teacher-directed activity such as dictation within the context of storybook reading (e.g., Dennis \& Votteler, 2013) or an interactive writing lesson (e.g., A. Hall, 2016) to support the children's emergent writing development, Joan and Leslie assisted the children as they directed their own natural/authentic interactions with print, interactions that engaged their interest in sign making (Myhill \& Jones, 2009; Peterson \& Portier, 2016; Worthington \& van Oers, 2017). Then, during individual childinitiated writing events, Joan and Leslie scaffolded the children's writing of individual words by asking questions, modelling strategies, and prompting the children to apply these strategies in their writing. At the end of the writing events, they acknowledged the children as writers by encouraging them to read their notes and letters.

By the time the Fairy Door scenario ended, Joan and Leslie had collected multiple samples of written texts from each of the children. These texts provided them with valid assessment opportunities. Based on their observations of the completed texts, the teachers learned about the graphic forms the children used to represent meaning (e.g., letters and/or words, identifiable images), what the children intended these forms to represent (e.g., individual sounds in words, complete sentence(s), characters), and how the children conveyed their message (e.g., subject and verb phrases, more complex information, positioning in picture). Furthermore, by working one on one with the children, they gained insight into the hypotheses the children made about print and their cultural knowledge about human relationships and interactions and how print can influence them (Rowe, 2009). 


\section{Final thoughts}

Imaginative play scenarios within kindergarten classrooms require minimal resources to set up and present young children with multiple occasions to engage in meaningful writing. Although this scenario was teacher initiated, the children's interests determined subsequent events within the scenario, with the teacher adopting a supporting role. By introducing an imaginative scenario in which a mysterious visitor established a home in the classroom, Joan and Leslie afforded the children in their kindergarten class the opportunity to direct their own learning by engaging in purposeful writing to extend the scenario's plotline. We offer the Fairy Door scenario as an example of how an imaginative scenario that embodies concepts within guided play can be used as pedagogical practice to support young children's emergent writing in the kindergarten classroom, while also providing educators with meaningful in-context opportunities to assess children's emergent writing. 


\section{References}

Byington, T. A., \& Kim, Y. (2016). Jump-starting pre-schoolers' emergent literacy: The entomologist tool kit. The Reading Teacher, 70(5), 601-604. doi:10.1002/trtr.1540

Dennis, L. R., \& Votteler, N. K. (2013). Preschool teachers and children's emergent writing: Supporting diverse learners. Early Childhood Education Journal, 41, 439-446. doi:10.1007/s10643-012-0563-4

Fisher, K. R., Hirsh-Pasek, K., Newcombe, N., \& Golinkoff, R. M. (2013). Taking shape: Supporting preschoolers' acquisition of geometric knowledge through guided play. Child Development, 84(6), 1872-1878.

Gerde, H. K., Bingham, G. E., \& Wasik, B. H. (2012). Writing in early childhood classrooms: Guidance for best practices. Early Childhood Education Journal, 40(6), 351-359. doi:10.1007/s10643-012-0531-z

Hall, A. H. (2016). Sustaining preschoolers' engagement during interactive writing lessons. The Reading Teacher, 70(3), 365-369. doi:10.1002/trtr.1521

Hall, N. (1991). Play and the emergence of literacy. In J. Christie (Ed.), Play and early literacy development (pp. 4-27). Albany, NY: SUNY Press.

Myhill, D., \& Jones, S. (2009). How talk becomes text: Investigating the concept of oral rehearsal in early years' classrooms. British Journal of Educational Studies, 57(3), 265-284. doi:10.1111/j.1467-8527.2009.00438.x

Ontario Ministry of Education. (2016). The kindergarten program. Toronto, ON: Queen's Printer for Ontario. Retrieved from http://www. edu.gov.on.ca/eng/curriculum/elementary/kinderprogram.html

Peterson, S. S. (2015). Dramatic play supports children's writing in kindergarten and grade one. Michigan Reading Journal, 8(1), 44-48. Retrieved from https://now-play.org/publications/

Peterson, S. S., Anderson, J., Kendrick, M., McTavish, M., Budd, K., Mayer, D., . . \& Riehl, D. (2016). Examining rhetorics of play in curricula in five provinces: Is play at risk in Canadian kindergartens? Canadian Journal of Education, 39(3), 1-26. Retrieved from http://www.cje-rce.ca/index.php/cje-rce

Peterson, S. S., \& Portier, C. (2016). Teaching vocabulary and writing in kindergarten through dramatic play centres. Colorado Reading Journal, 27, 25-32.

Quinn, M. F., Gerde, H. K., \& Bingham, G. E. (2016). Help me where I am: Scaffolding writing in preschool classrooms. The Reading Teacher, 70(3), 353-357. doi:10.1002/trtr.1512

Rowe, D. W. (2009). Early written communication. In R. Beard, D. Myhill, J. Riley, \& M. Nystrand (Eds.), The SAGE handbook of writing development (pp. 213-231). London, UK: SAGE.

Vygotsky, L. (1978). Mind in society. Cambridge, MA: Harvard University Press.

Wajskop, G., \& Peterson, S. S. (2015). Dramatic play as a meaning-making and story-making activity. Early Childhood Education, 43(1), 17-20. Retrieved from https://now-play.org/publications/

Wasik, B. A., \& Jacobi-Vessels, J. L. (2017). Word play: Scaffolding language development through child-directed play. Early Childhood Education Journal, 45, 769-776. doi:10.1007/s10643-016-0827-5

Weisberg, D. S., Kittredge, A. K., Hirsh-Pasek, K., Golinkoff, R. M., \& Klahr, D. (2015). Making play work for education. Phi Delta Kappan, 96(8), 8-13.

Worthington, M., \& van Oers, B. (2017). Children's social literacies: Meaning making and the emergence of graphical signs and texts in pretence. Journal of Early Childhood Literacy, 17(2), 147-175. doi:10.1177/1468798415618534 